\title{
Uso da calculadora gráfica na exploração de modelos contínuos não lineares
}

\author{
The use of graphing calculator in the exploration of nonlinear continuous models
}

\author{
Floriano Viseu \\ fviseu@ie.uminho.pt \\ Sara Campos \\ sgabrielacampos@gmail.com \\ José António Fernandes \\ jfernandes@ie.uminho.pt \\ Helena Rocha \\ hcr@,fct.unl.pt
}

\begin{abstract}
Resumo
A integração da calculadora gráfica na realização de atividades matemáticas faz com que os alunos expressem muitos dos seus processos e das suas formas de pensar. Como no ensino secundário algumas dessas atividades são realizadas com a calculadora gráfica, pretendemos averiguar o contributo deste recurso na promoção da aprendizagem de modelos contínuos não lineares de alunos do $11 .^{\circ}$ de Matemática $\mathrm{B}^{1}$. Adotando uma metodologia qualitativa, recolhemos e analisamos as produções escritas dos alunos. No início, os alunos tendem a registar a informação que retiram da calculadora sem justificar o que apresentam. À medida que adquirem habilidade de usar este recurso, tendem a definir a janela de visualização que lhes permite visualizar representações gráficas das funções que modelam as situações problema com que se depararam e relacionar diferentes menus no estudo de características dessas funções. Tais procedimentos fazem com que o registo da informação que retiram da calculadora seja acompanhado da justificação dos seus raciocínios e da validação das conjeturas que estabelecem.
\end{abstract}

Palavras-chave: Calculadora gráfica; Aprendizagem de modelos contínuos não lineares; Alunos do $11 .^{\circ}$ ano de escolaridade.

\begin{abstract}
The integration of the graphing calculator in mathematical activity encourages students to express many of their processes and ways of thinking. Since some of the activities at the high school level are carried out with the graphing calculator, we intend to investigate the contribution of this resource to promote the learning of nonlinear continuous models in the 11th grade. By adopting a qualitative methodology, we collected and analysed the students' writing productions. At first, students used to present the information given by the calculator with no justification. As they acquire skills in the use of this resource, they usually set up the viewing window in order to visualize the graphical representations of functions that model the problem situation they are working on and also relate the different existing menus in the study of those functions characteristics. Such procedures make students to present the data collected in the calculator with a justification of their arguments and a validation of their conjectures.
\end{abstract}

Keywords: Graphing Calculator; Learning of nonlinear continuous models; 11 th grade students.

\footnotetext{
${ }^{1} \mathrm{O}$ sistema de ensino português engloba 12 anos antes da entrada no ensino superior, assim como a generalidade dos países do mundo. Desses anos, os primeiros nove correspondem ao ensino básico e os três últimos ao ensino secundário. Nos tês anos de ensino secundário, no qual os alunos começam a ser encaminhados para um grupo de cursos do ensino superior, os currículos da disciplina de Matemática divergem, de acordo com os cursos Científico-Humanísticos de Ciências e Tecnologias e de Ciências Socioeconómicas (Matemática A), CientíficoHumanístico de Artes Visuais, Tecnológicos de Construção Civil e Edificações, Eletrotecnia e Eletrónica, Informática, Administração, Marketing e de Desporto (Matemática B), e de Ciências Sociais e Humanas (Programa de Matemática Aplicada às Ciências Sociais (MACS)).
} 


\section{Introdução}

No acompanhamento da prática pedagógica de futuros professores de matemática, como formadores de professores, constatamos que a calculadora gráfica é mais utilizada como um auxiliar de cálculos do que na realização de atividades de descoberta e de exploração. Como a calculadora é um material didático de uso obrigatório na aula de matemática do ensino secundário português e atendendo às dificuldades que muitos alunos revelam ter na atividade matemática, consideramos pertinente tirar partido deste recurso na promoção da aprendizagem. A nossa intenção é corroborada pelas recomendações metodológicas do programa do ensino secundário, onde se defende que as estratégias de ensino devem assegurar atividades em que os alunos "descrevam os raciocínios utilizados e interpretem aquilo que se lhes apresenta" (Ministério da Educação, 2001, p. 16). A concretização destas atividades levou-nos a identificar contributos da utilização da calculadora gráfica na aprendizagem de modelos contínuos não lineares por alunos do $11 .^{\circ}$ ano de Matemática $\mathrm{B}^{2}$.

Os princípios e métodos de trabalho da disciplina de Matemática concorrem para a educação do aluno, contribuindo para o desenvolvimento da sua autonomia e solidariedade, responsabilidade e consciência das relações e a sua envolvência no meio ambiente em que vive. A disciplina de Matemática é uma parte imprescindível da cultura científica e humanística, preparando o aluno para adquirir flexibilidade em adaptar-se a novas situações, para que se sinta motivado a continuar a sua formação ao longo da vida. Além disso, a disciplina de Matemática é também de enorme ajuda na construção do diálogo na comunicação com os outros, fornecendo instrumentos de compreensão, seleção, avaliação e integração das mensagens e o acesso a fontes de conhecimento científico. Perante os desafios de raciocinar e pensar matematicamente e, consequentemente, transmitir as suas ideias, quer oralmente quer por escrito, os alunos desenvolvem a sua capacidade de argumentação matemática. Em particular, a comunicação escrita ajuda os alunos a consolidar o seu raciocínio, uma vez que os leva a refletir sobre o seu trabalho e a clarificar as suas próprias ideias acerca dos conceitos desenvolvidos na aula, o que enriquece o seu pensamento quando

\footnotetext{
${ }^{2}$ Como na generalidade dos países, o sistema de ensino português, anterior ao ensino superior, engloba 12 anos de escolaridade. Desses anos de escolaridade, os primeiros nove correspondem ao ensino básico e os três últimos ao ensino secundário. No ensino básico, constituído por três ciclos: o primeiro de quatro anos e em regime de monodocência; o segundo de dois anos e o terceiro de três anos, o currículo da disciplina de Matemática é igual para todos os alunos. Nos tês anos de ensino secundário, em que os alunos começam a ser encaminhados para diferentes cursos, tendo em vista a continuação de estudos ou a integração na vida ativa, os currículos da disciplina de Matemática divergem, consoante seguem cursos de Ciências e Tecnologias e de Ciências Socioeconómicas (Matemática A), Cursos de Ciências Socias e Humanas (Matemática Aplicada às Ciências
} Sociais) ou Cursos Tecnológicos (Matemática B). 
apresentam os seus métodos de resolução ou quando justificam o seu raciocínio (NCTM, 2007).

A tecnologia, em particular a calculadora gráfica, veio mudar a dinâmica da aula de Matemática e a forma de resolver as tarefas matemáticas. Segundo Burril (2008), os alunos com a calculadora gráfica podem explorar conceitos matemáticos de novas formas e com maior profundidade, permitindo estabelecer ligações entre as várias representações (gráfica, numérica e algébrica). Importa que os alunos transcrevam estas representações de forma adequada, aliando a tecnologia à comunicação, em particular a comunicação escrita. Os alunos ao transcreverem para o caderno o que retiram da calculadora, juntamente com a devida justificação, desenvolvem a capacidade de comunicar claramente o seu raciocínio matemático, considerada uma competência essencial (Ball, 2003). Colocar uma ideia no papel requer uma reflexão cuidadosa e atenta, ajudando a aprender e a reter os conceitos explorados.

Desde que foi introduzida nos programas de Matemática, em 1997, a calculadora é um dos recursos tecnológicos mais utilizado nas aulas. Com a evolução da tecnologia, os alunos possuem calculadoras cada vez mais poderosas e com mais funcionalidades. Segundo Anderson et al. (1999), a calculadora veio mudar a dinâmica da aula de matemática e a forma de resolver problemas, visto que, "tradicionalmente, tanto a formulação do problema matemático como a interpretação da solução eram vistos pelos professores com menor importância em comparação com o processo de resolução do problema" (p. 498). Para estes autores, com a ajuda da calculadora na resolução de problemas, os alunos têm mais possibilidades de desenvolver capacidades cognitivas elevadas. Significa isso, tal como defendem Fernandes e Vaz (1998), que "a simplificação do cálculo permite mais tempo para explorar atividades matemáticas mais profundas e significativas" (p. 44).

Ball e Stacey (2003) defendem que usar a calculadora na sala de aula exige uma atenção cuidada sobre o que constitui um bom registo escrito, fornecendo novas oportunidades na resolução de problemas. Para auxiliar alunos e professores a alterar a natureza dos registos escritos que elaboram, com base na calculadora gráfica, estas autoras apresentam as seguintes diretrizes: (i) anotar todo o raciocínio (R); (ii) anotar toda a informação envolvida (I), incluindo a sintaxe da calculadora; (iii) certificar que o plano a seguir é claro (P); e (iv) selecionar a informação (A), pois nem todos os passos intermédios são necessários. Estas diretrizes, designadas pelo acrónimo RIPA, permitem organizar a atividade do aluno com a calculadora gráfica na aula de matemática. 


\section{Modelos contínuos não lineares no currículo de Matemática}

A disciplina de Matemática $\mathrm{B}$, embora permita também o prosseguimento de estudos, faz parte dos cursos mais orientados para a vida ativa, apresenta uma natureza mais prática e tem uma duração bienal no curso de Artes Visuais, que é o curso a que pertenciam os alunos que participaram no presente estudo. Segundo o programa de Matemática B, de um modo geral, a Matemática é indissociável da cultura científica e humanística, impulsionando os alunos a fazerem escolhas profissionais, a adaptarem-se a mudanças tecnológicas e fornecendo-lhes estratégias que os motivam a continuar a sua formação ao longo da vida. É também um contributo essencial na construção do discurso através do qual os alunos comunicam entre si, bem como fornecendo "instrumentos de compreensão mais profunda, facilitando a seleção, avaliação e integração de mensagens necessárias e úteis, ao mesmo tempo que fornece acesso a fontes de conhecimento científico a ser mobilizado sempre que necessário" (Ministério da Educação, 2001, p. 3). Para a concretização destas competências muito contribuem as tarefas de modelação (Ponte, 2005) que são também uma preocupação do Programa de Matemática $\mathrm{B}$, tal como podemos constatar no quadro dos objetivos e das competências gerais, uma vez que

\footnotetext{
constituem tanto a metodologia de trabalho privilegiada na construção dos conceitos matemáticos como uma competência a desenvolver que é imprescindível para estudantes que vão enfrentar no seu trabalho profissional problemas concretos muito variados e terão de saber selecionar as ferramentas matemáticas relevantes para cada situação. (Ministério da Educação, 2001, p. 16).
}

O aluno deverá, então, ser capaz de utilizar a Matemática na interpretação do real, através da análise de uma determinada situação do seu dia-a-dia, escolhendo estratégias de resolução, criando ou selecionando um modelo que se ajuste à situação em questão. Esse modelo irá constituir "uma representação duma dada situação, através de objetos, relações e estruturas com que se procura descrever os elementos considerados fundamentais dessa situação, ao mesmo tempo que se ignoram deliberadamente os elementos tidos como secundários" (Ponte, 1990, p.5).

Em particular, o Programa de Matemática B defende o estudo de três modelos, que fazem parte da temática Modelos Contínuos Não Lineares: (i) Exponencial, que pode ser introduzido para resolver problemas de evolução das populações, poluição, temperaturas, drogas no sangue, materiais radioativos, entre outros; (ii) Logarítmico, usado em tarefas de, por exemplo, medição da intensidade de um sismo, intensidade de um dado som, medição de PH; e (iii) Logístico, que se trata de um modelo mais realista da evolução do crescimento populacional. Deste modo, pretende-se que os alunos sejam capazes de reconhecer e dar 
exemplos de situações em que os modelos exponenciais sejam aplicados com eficácia; usar propriedades das exponenciais; usar as calculadoras gráficas para encontrar valores ou representar gráficos que respondam a possíveis mudanças nos parâmetros; predizer e interpretar o gráfico de uma função; descrever regularidades; obter formas equivalentes de expressões exponenciais; definir o número de Neper e o logaritmo natural de um número; e resolver equações simples usando exponenciais e logaritmos, no contexto da resolução de problemas, fazendo também apelo ao recurso às tecnologias, à capacidade de resolução de problemas, às atividades investigativas ou de modelação matemática com vista à concretização de aprendizagens significativas (Ministério da Educação, 2001).

\section{A calculadora gráfica na aula de matemática}

A utilização da tecnologia na aula de matemática tem como objetivo favorecer uma aprendizagem mais profunda, pois permite uma abordagem mais indutiva da Matemática e o desenvolvimento das suas aplicações (Fernandes \& Vaz, 1998). A tecnologia deve ser utilizada não com o intuito de substituir a compreensão e intuição mas sim com o papel de estimulá-las, com a finalidade de enriquecer a aprendizagem matemática dos alunos (NCTM, 2007). A este respeito, Fernandes, Alves, Viseu e Lacaz (2006), a partir da análise dos programas de Matemática do ensino secundário, concluíram que:

\footnotetext{
Todos os usos da tecnologia referidos [nos programas] relevam uma abordagem indutiva e experimental da matemática, perspectivando-se a sua utilização nos momentos de introdução, consolidação e aprofundamento de conceitos. Na fase de introdução, enfatiza-se uma abordagem intuitiva geradora de regularidades, padrões e ideias; na fase de consolidação, destacam-se as possibilidades da tecnologia na exploração de exemplos e como ferramenta de apoio à resolução de problemas; e, finalmente, na fase de aprofundamento, abordam-se novas questões surgidas nos dois momentos anteriores. (p.325)
}

De acordo com o programa de Matemática B, "não é possível atingir os objetivos gerais e competências deste programa sem recorrer à dimensão gráfica, e essa dimensão só é plenamente atingida quando os estudantes traçam uma grande quantidade e variedade de gráficos com apoio de tecnologia adequada" (Ministério da Educação, 2001, p. 14). Segundo ainda este documento, as calculadoras gráficas são ferramentas que se utilizam com mais frequência e devem ser entendidas como potenciadores do espírito de pesquisa do aluno e não só usada para efetuar meros cálculos. O programa de Matemática B menciona, também, como vantagens a abordagem numérica de problemas, a modelação, a simulação e resolução de situações problemáticas e a investigação e exploração de relações entre diferentes representações para uma situação problemática, entre outras. Almeida e Oliveira (2009), num 
estudo sobre o uso da calculadora gráfica no ensino de funções, concluem que a possibilidade que a calculadora oferece de visualizar o efeito da mudança de parâmetros no gráfico de uma função faz com que os alunos possam percecionar "a matemática de uma forma dinâmica, para seu entendimento conceptual da álgebra como meio de representação e para o desenvolvimento da capacidade de estabelecerem conexões entre a expressão analítica e a representação gráfica de uma função" (p. 112).

Para Ponte et al. (1997), utilizar a calculadora gráfica durante a resolução de tarefas é uma forma de estimular os alunos a formar conjeturas e a desenvolver a capacidade de investigar e desenvolver raciocínios e argumentos. No entanto, a tecnologia só por si não substitui o professor de matemática. Ela pode ser utilizada de forma eficaz ou não, tudo dependendo do professor e da forma como este a utiliza. Nas atividades de aprendizagem, Waits e Demana (1994) referem três formas de integrar a calculadora no ensino da matemática: (1) começar por resolver um exercício ou problema com papel e lápis e, seguidamente, utilizar a calculadora para verificar a resolução; (2) começar por resolver um exercício ou problema com a calculadora e, depois, confirmar ou completá-lo com papel e lápis; e (3) resolver um exercício ou problema apenas com a calculadora, pois a sua resolução através de outros meios é impraticável ou mesmo impossível. Deste modo, o uso da calculadora deve ser integrado nas aulas tanto para confirmar resultados como para gerar ideias a serem provadas por processos analíticos e para efetuar cálculos e representações que de outra forma seriam impossíveis ou muito morosos.

O professor desempenha um papel importante no uso da calculadora, evitando que os alunos se tornem dependentes da sua utilização. É da sua responsabilidade que seja feita uma utilização inteligente da calculadora gráfica, tendo para isso que planificar as tarefas de forma adequada ao seu uso e para que seja o aluno a decidir se deve ou não utilizar a calculadora nessas mesmas tarefas (Burril et al., 2002). As calculadoras vieram proporcionar um novo tipo de tarefas, questões e estratégias de ensino e aprendizagem a desenvolver dentro da sala de aula (Dunham \& Dick, 1994). Com o tempo, os alunos habituam-se a tirar o devido partido das calculadoras gráficas, o que, segundo Ruthven (1993), aumenta a sua confiança em explorá-la nas atividades que realizam. Quando começam a utilizar a calculadora gráfica, a autora considera que os alunos a veem como uma forma automática de realizar um conjunto limitado de procedimentos, tais como determinar valores de funções ou representá-las graficamente. $\mathrm{O}$ aumento de confiança na sua utilização pode, contudo, dar origem a novas utilizações, a mais promissora das quais é o recurso ao método de tentativa e erro. Com efeito, 
embora este método tenha limitações, constitui uma forma de os alunos abordarem problemas que de outro modo estariam para além das suas possibilidades. A autora é apologista de que o poder da calculadora gráfica reside na possibilidade de facilitar uma abordagem na sala de aula onde, inicialmente, as relações matemáticas são exploradas através da sua representação numérica ou gráfica de casos particulares. Ruthven (1993) tem reservas sobre o tipo de ensino que se baseia fortemente na representação simbólica, porque essa abordagem tende a separar o argumento matemático do seu contexto original e o enfoque passa a ser o símbolo como objeto em si mesmo.

\section{Metodologia de investigação}

Com este estudo pretendemos identificar contributos da utilização da calculadora gráfica na aprendizagem de modelos contínuos não lineares por alunos do $11 .^{\circ}$ ano de Matemática B. Foi nesta temática que uma futura professora, que é um dos autores do artigo, desenvolveu a sua prática pedagógica supervisionada. Nas suas estratégias de ensino, os tópicos dos modelos não lineares (traduzidos pelas funções exponencial, logarítmica e logística) foram estudados a partir de tarefas que implicavam, na maior parte delas, a utilização da calculadora gráfica. Esta experiência decorreu durante 15 aulas. Atendendo à natureza do objetivo delineado, adotámos uma abordagem qualitativa e interpretativa na procura de compreender a atividade dos alunos na resolução de tarefas em contexto de sala de aula (Bogdan \& Biklen, 1994). Com esta finalidade, os dados foram recolhidos através dos registos escritos que os alunos produziram, em pares, na resolução das tarefas propostas com recurso à calculadora gráfica. A turma onde se realizou esta experiência era do $11 .^{\circ}$ ano de Matemática B, do curso de Artes Visuais, composta por 16 alunos, 5 rapazes e 11 raparigas, com média de idades de, aproximadamente, 16 anos. Em relação às preferências referidas pelos alunos, a maior parte mencionou que a disciplina de Desenho era uma das suas disciplinas favoritas; apenas três referiram Matemática como uma das disciplinas favoritas e nove referiram que a Matemática era a disciplina de que menos gostavam, pois era nela que sentiam maiores dificuldades. Considerando o desempenho dos alunos, numa escala de zero a 20 valores, a classificação média no final do ano letivo foi de, aproximadamente, 13 valores, tendo quatro alunos obtido uma classificação negativa (inferior a 10 valores). Em termos de comportamento e participação, a turma era composta por alunos ativos e participativos, que não tinham qualquer problema em expor as suas dificuldades e receios, embora em algumas aulas fosse difícil envolvê-los nas atividades já que se distraíam muito facilmente.

Para evidenciar a atividade dos alunos a partir da utilização da calculadora gráfica, a informação recolhida é analisada e apresentada segundo as seguintes categorias, adaptadas de 
Ball e Stacey (2003) e já antes referidas: (i) Informação que os alunos escrevem quando recorrem à calculadora (esboço de gráficos sem qualquer justificação); (ii) Estratégias de utilização da calculadora gráfica (definição da janela de visualização e relação entre diferentes menus da calculadora gráfica); e (iii) Raciocínio (verbalização, apresentação e registo de raciocínios, formulação de generalizações e validação de conjeturas).

\section{Análise de resultados}

A caracterização da utilização da calculadora gráfica na aprendizagem de modelos contínuos não lineares é organizada a partir das três categorias antes referidas, que são estudadas na exploração de várias tarefas pelos alunos.

\section{Informação}

Na perspetiva de Stacey e Ball (2003), a categoria informação refere-se a verificar se o aluno usa notação matemática em vez de sintaxe da calculadora gráfica nas suas respostas e se ilustra a informação com gráficos e tabelas sem apresentar qualquer justificação. Inicialmente, os alunos recorrem à notação matemática sem fazer referência à linguagem da calculadora. Por exemplo, os alunos registam o esboço gráfico de uma dada função sem referir os comandos que lhes permitem editar a expressão no menu de funções. Na fase de introdução dos modelos contínuos não lineares, os alunos não tinham conhecimento de qualquer um dos modelos estudados. Para evidenciar esta atividade, os alunos resolveram a seguinte tarefa:

Um jovem agricultor tem uma estufa onde produz alfaces todo o ano. No interior da estufa há um sistema computorizado que permite controlar a temperatura e a humidade relativa do ar. Sejam $f$ e $g$ as funções que, num determinado dia, relacionam a temperatura em graus Celsius com a hora do dia, respetivamente no interior e no exterior da estufa:

$$
f(t)=10+\frac{100}{(t-10)^{2}+20} ; 0 \leq t \leq 24 \text { e } g(t)=6+\frac{35 t-250}{t^{2}-20 t+110} ; 0 \leq t \leq 24
$$

A amplitude térmica, num dado intervalo de tempo, é dada pela diferença entre as temperaturas máxima e mínima nesse intervalo de tempo. Mostra que a amplitude térmica no exterior da estufa, no dia a que se refere a informação dada, foi inferior a $15^{\circ} \mathrm{C}$.

$\mathrm{Na}$ tua resposta deves apresentar:

- A temperatura mínima, arredondada às milésimas

- A temperatura máxima, arredondada às milésimas

- A amplitude térmica, arredondada às centésimas. 
No texto da tarefa está explícito a atenção a ter na representação do gráfico da função através da consideração do seu domínio, como comprova o registo efetuado por um par de alunos.

Figura 1: Representação gráfica sem informação escrita na resposta (P7).

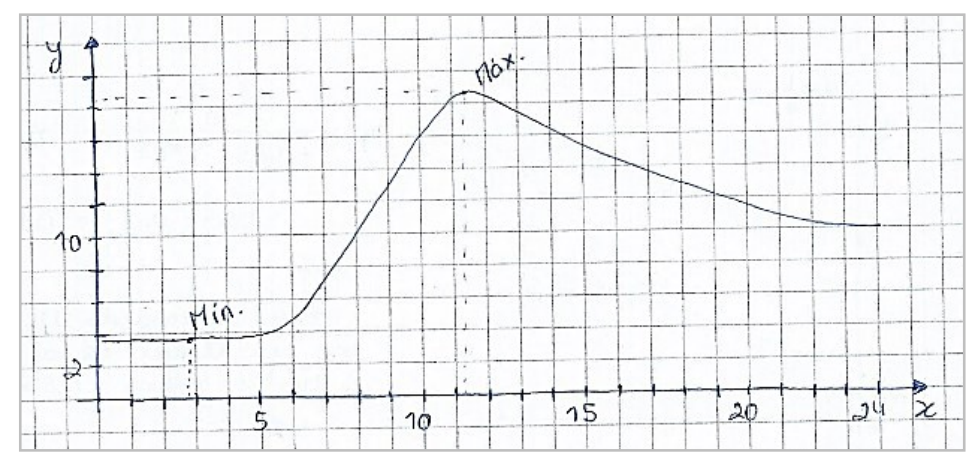

Os alunos transcreveram o gráfico para o papel tendo em conta o domínio apresentado, delimitando o esboço gráfico, o que se traduziu no cuidado de não incluir valores negativos e de não prolongar esse esboço para além do limite superior dos valores considerados, valores que a variável $t$ poderia assumir. No entanto, apenas apresentam o gráfico indicando qual o valor mínimo e máximo e não retiram mais informação da calculadora para poderem responder à questão formulada.

Outro exemplo em que alguns alunos transcrevem para o papel a representação gráfica de uma função obtida na calculadora gráfica, que representa a situação-problema, sem responder à tarefa proposta, verificou-se no estudo da concentração de um fármaco no sangue:

Admite que a concentração do fármaco "Saratex", em miligramas por litro de sangue, $t$ horas após a administração a um doente, é dada pela expressão $C(t)=t \times 1,05^{-2 t}$. Durante quanto tempo a concentração do fármaco no sangue é superior ou igual a 2,5 miligramas por litro?

Figura 2: Representação gráfica sem resposta escrita (P2).

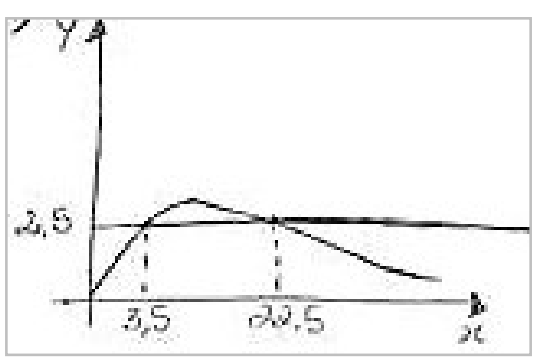

Nesta resolução, o par P2 reproduziu o gráfico na folha, indicando os pontos da interseção dos gráficos das funções $y_{1}=2,5$ e $y_{2}=x \times 1,05^{-2 x}$, mas não apresentou qualquer justificação ou explicação. Este tipo de situações, em que apenas é apresentada a representação gráfica sem dar a resposta à tarefa, aconteceu mais nas primeiras aulas. Com o hábito de utilizarem a calculadora gráfica e, sobretudo, de registar e interpretar o máximo de 
informação que podiam dela retirar, os alunos começaram a aperceber-se da importância da estratégia que delineavam no ato de recorrer à calculadora.

\section{Estratégias de utilização da calculadora gráfica}

Para além da informação que retira da calculadora, ao nível da representação gráfica, o aluno tem que ser capaz de definir corretamente a janela de visualização e relacionar diferentes menus da calculadora gráfica.

Definição da janela de visualização. Quanto à definição da janela de visualização, na resolução de tarefas, principalmente tarefas de contexto real, há que atender ao 'comportamento' da função representada pela expressão que modela a situação dada para ser devidamente apresentada na calculadora gráfica, o que interessa no contexto do problema e como se transcreve essa informação. Os alunos manifestam cuidado em designar as variáveis dos eixos cartesianos, mas tendem a considerar as letras que são consideradas na calculadora gráfica, $x$ e $y$, e não as variáveis que contextualizam o problema, como ilustra o registo que os alunos efetuaram na resolução de um problema aquando do estudo da função logarítmica e da função logarítmica como inversa da função exponencial (Figura 3):

Um estudo experimental sobre uma determinada espécie vegetal iniciou-se com 500 exemplares, sendo feito o acompanhamento da evolução ao longo dos anos. O número de exemplares existentes, passados $t$ anos do início da experiência, é dado pelo modelo: $E(t)=500 \times e^{0,45 t}$.

$\mathrm{Na}$ resolução das questões seguintes, utiliza dois processos: representações gráficas e logaritmos. Os resultados devem ser dados em anos e meses e os meses arredondados às unidades.

O estudo é dado como concluído quando o número de exemplares atingir 10000. Qual é o tempo previsto para a realização deste estudo?

Figura 3: Resolução gráfica e analítica da questão proposta (P3).

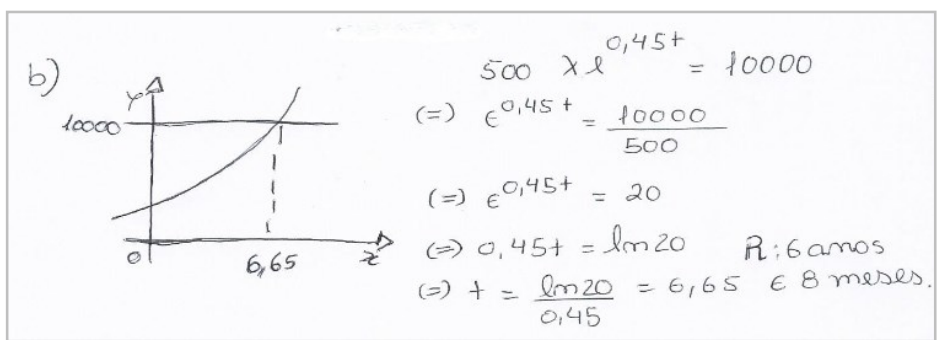

$\mathrm{Na}$ modelação do número de exemplares da espécie vegetal ao longo de uma experiência, esperava-se que os alunos indicassem o tempo $(t)$ previsto para se atingir os 10 000 exemplares (correspondentes a $E(t))$. Nesta resolução, constata-se que os alunos recorreram aos dois processos, tal como era pedido. Na resolução gráfica, representaram os 
esboços gráficos das duas funções $y_{1}=10000$ e $y_{2}=500 \times e^{0,45 t}$ e, de seguida, determinaram o ponto de interseção desses gráficos para responderem à questão formulada. Porém, na transcrição da informação da calculadora para o papel, os alunos não atenderam ao contexto do problema, visto que não restringem o domínio da função na janela de visualização (que também não é apresentada) de modo a não se considerarem tempos negativos. Este problema já não acontece na resolução analítica porque a solução encontrada insere-se no domínio de validade da condição formulada.

À medida que os alunos adquirem habilidade em trabalhar com a calculadora, apercebem-se da importância de considerar uma janela de visualização que se adequa ao contexto do problema, como exemplifica a resolução dos alunos à seguinte tarefa:

A quantidade $Q$ de cafeína num indivíduo, $t$ horas após a ingestão da mesma, é dada pela expressão $Q=Q_{0} \times a^{-t}$. Um indivíduo tomou uma chávena de café que contém $80 \mathrm{mg}$ de cafeína. Sabe-se que o tempo de semivida da cafeína no organismo é de, aproximadamente, 4 horas.

Informação suplementar: A semivida de uma substância cuja quantidade decresce é o tempo necessário para que essa quantidade passe a metade. Admite que para valores inferiores a $15 \mathrm{mg}$ de cafeína no organismo a mesma deixa de exercer efeitos estimulantes. Determina graficamente, recorrendo à calculadora, o período de tempo em que a cafeína funcionou como estimulante. Apresenta o resultado em horas e minutos (os minutos arredondados às unidades).

Figura 4: Esboço gráfico que traduz o momento em que a cafeína deixa de exercer efeitos (P5).

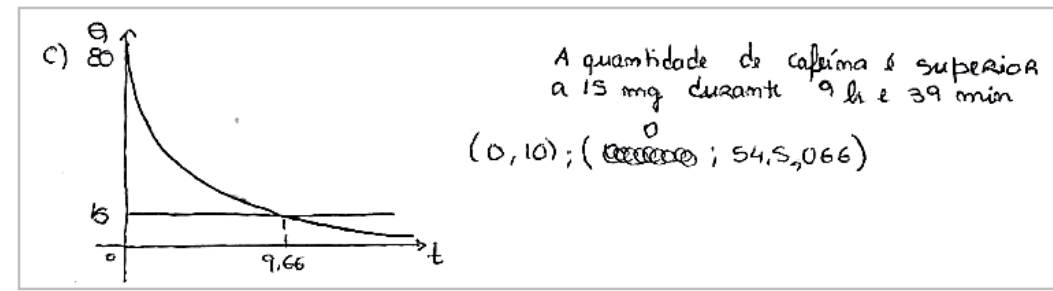

Nesta resolução, os alunos tiveram em conta o domínio da função segundo o contexto do problema: a variável independente é o tempo $(t)$, logo não consideraram o semieixo negativo $O x$, e a variável dependente é a quantidade de cafeína presente no organismo de um indivíduo passado o tempo $t(Q(t))$, não fazendo também sentido considerar o semieixo negativo $O y$. Atendendo a estas características, os alunos indicaram a janela de visualização que utilizaram, embora num formato que não é usual (trocaram os parênteses retos por curvos), o que permite ao professor ou aos seus colegas reproduzir o mesmo esboço gráfico. Como era pedido o período de tempo em que a cafeína funciona como estimulante, sabendo que esta deixa de exercer esse efeito para valores inferiores a 15mg de cafeína, os alunos 
representaram graficamente as funções $y_{1}=15$ e $y_{2}=80 \times 2^{-\frac{t}{4}}$ para determinar o ponto de interseção dos respetivos gráficos. Nesta representação, a maior parte dos alunos definiu uma janela de visualização que lhes permitiu interpretar e responder à questão colocada.

Relacionar os diferentes menus. Com a calculadora gráfica, os alunos têm acesso a diferentes menus, tais como de estatística, cálculo, gráfico, tabela e dinâmico. Na resolução de algumas tarefas propostas, os alunos poderiam recorrer ao menu gráfico e ao menu tabela. Nem sempre foi preciso recorrer simultaneamente a estes dois menus, o que só aconteceu em função da natureza da tarefa proposta. Por exemplo, no estudo do número de Neper importava que os alunos estabelecessem conexões entre a informação expressa quer pelo menu gráfico quer pelo menu tabela para compreenderem como se obtém este número. Para tal, foi proposta a seguinte tarefa:

A Maria depositou $6000 €$ num banco à taxa anual de $10 \%$ de juros. O banco pratica capitalizações (número de vezes que os juros são acrescentados ao capital, ao longo do ano) variáveis: anual, semestral, trimestral, mensal e diária. Analisa o que acontece se a Maria pudesse optar por uma capitalização a todo o instante.

Figura 5: Relação entre diferentes menus da calculadora gráfica (P4).

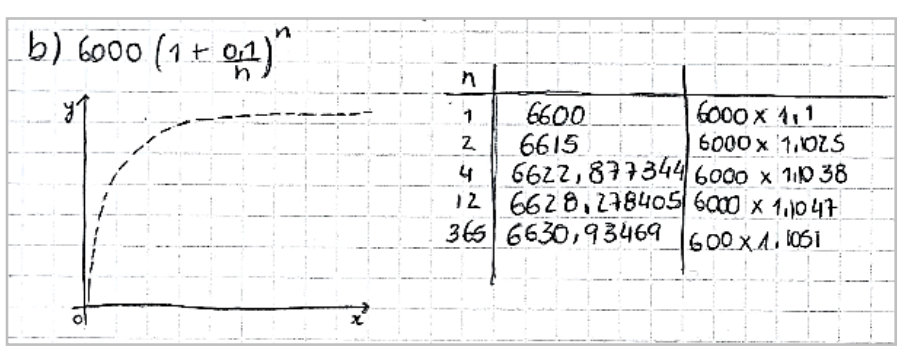

Os alunos puderam assim determinar, através do confronto entre os valores da tabela e a visualização da representação gráfica da situação, o fator de capitalização do dinheiro depositado no banco a todo o instante. Neste registo, os alunos indicam as variáveis nos eixos, novamente $x$ e $y$, mas não traçam a assíntota horizontal porque a calculadora não lhes fornece essa informação. Por outro lado, ao traçar o esboço do gráfico a partir da origem não consideram que o zero não faz parte do domínio da função. Quando se atribui à variável independente valores na vizinhança de zero, à sua direita, a função tende para valores próximo de 6000 e não de zero. Este lapso registado pelos alunos deveu-se ao facto de na janela de visualização que consideraram não ser possível 'ver' o eixo das abcissas. Ao transporem a informação da calculadora para o papel não revelaram capacidade crítica para confrontar o esboço obtido com o comportamento dos valores expressos na tabela. 
A discussão da tarefa permitiu introduzir o número de Neper através da visualização do comportamento do gráfico da sucessão $\left(1+\frac{1}{n}\right)^{n}$, dos valores expressos na tabela e do enquadramento dos termos da sucessão, como mostra o seguinte registo efetuado por um par de alunos:

Figura 6: Introdução do número de Neper (P4).

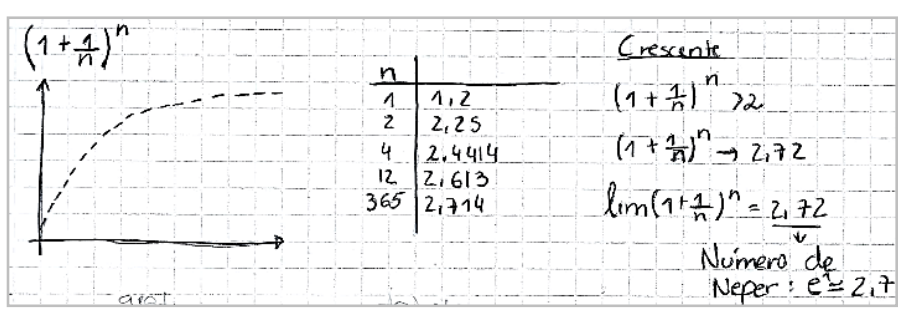

Nesta resolução, os alunos usaram três tipos de representação (gráfica, tabular e analítica). Na tabela, os alunos aperceberam-se de que à medida que o valor de $n$ aumenta, os termos da sucessão aproximam-se de 2,7. No gráfico, não apresentaram as variáveis dos eixos nem a assíntota horizontal. A associação da informação presente nestas duas representações levou os alunos a registarem que a sucessão é estritamente crescente, logo o conjunto dos seus termos é minorado pelo primeiro, determinado erradamente na tabela, e majorado pelo limite dos termos da sucessão.

Noutras situações, os alunos recorreram a outros menus, como, por exemplo, aos menus gráfico e estatístico, na resolução de uma tarefa que tratava do crescimento populacional no mundo entre os anos de 1900 e 2000 (inclusive).

A população mundial, desde 1900 até 2000, evolui segundo os valores da tabela abaixo:

\begin{tabular}{|c|c|}
\hline Ano & Número de pessoas (em milhares de milhões) \\
\hline 1900 & 1,65 \\
\hline 1910 & 1,75 \\
\hline 1920 & 1,86 \\
\hline 1930 & 2,07 \\
\hline 1940 & 2,30 \\
\hline 1950 & 2,56 \\
\hline 1960 & 3,04 \\
\hline 1970 & 3,71 \\
\hline 1980 & 4,45 \\
\hline 1990 & 5,28 \\
\hline 2000 & 6,08 \\
\hline
\end{tabular}

Admite que a variável independente designa o número de anos após 1900. Estima a população mundial para 2010.

Determina a expressão de uma função que se ajuste aos dados da tabela, percorrendo as seguintes etapas:

- Considera o ano de 1900 como o ano zero (0), o ano 1910 como o ano dez (10), e assim sucessivamente até ao ano de 2000 como o ano cem (100);

- Escreve essa expressão (apresenta os valores numéricos envolvidos na expressão e fornecidos pela calculadora, com quatro casas decimais);

- Usando essa expressão, estima a população mundial para 2010 (apresenta o resultado em milhares de milhões de habitantes, arredondado às centésimas). 
Depois da introdução dos dados em listas estatísticas, os alunos teriam de recorrer ao menu estatístico da calculadora gráfica, tendo em atenção que o ano 1900 correspondia ao ano zero, o ano 1910 ao ano 1 e assim sucessivamente. Como o comportamento da nuvem de pontos dava a entender que o gráfico seria de uma função exponencial, alguns alunos ponderaram que poderia traduzir uma função logística, assunto que foi tratado na aula anterior. Após a clarificação no grupo turma acerca do melhor modelo de ajustamento aos dados representados, os alunos registaram a informação que retiraram do menu gráfico e do menu estatístico, como mostra a seguinte resolução de um par de alunos:

Figura 7: Relação entre os menus gráfico e estatístico da calculadora gráfica (P5).

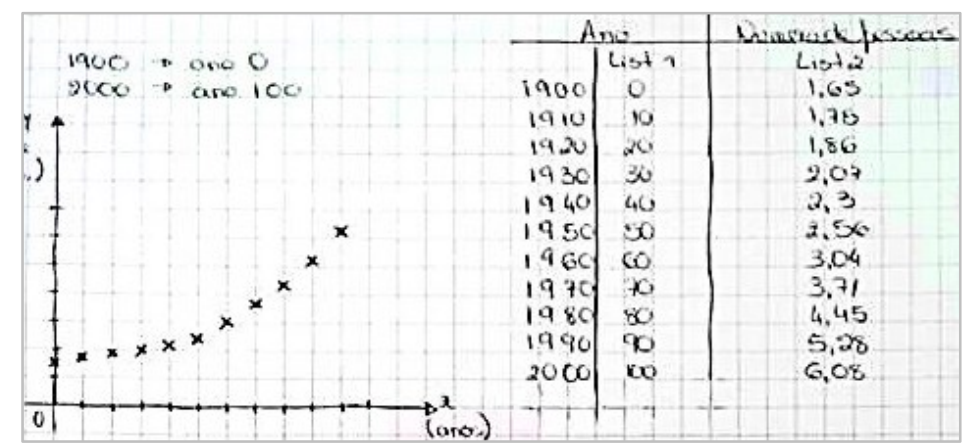

Os alunos voltam a representar as variáveis com as letras $x$ e $y$ nos eixos, apesar de fazerem referência ao ano e ao número de pessoas. Em geral, os alunos tendem a indicar as letras $x$ e $y$ para representar as variáveis no sistema de eixos cartesiano, em vez de considerar as letras que contextualizam o problema em questão, o que pode ser consequência da calculadora gráfica, uma vez que são essas as letras que aparecem no menu de edição das expressões que representam funções na calculadora. Compete aos alunos fazerem essa conversão, os quais, geralmente, mostraram ter essa perceção quando raciocinaram sobre as atividades que desenvolveram na sala de aula, sobretudo quando recorreram à calculadora gráfica.

\section{Raciocínio}

A utilização da calculadora gráfica impele o aluno a verbalizar, apresentar e registar os seus raciocínios e a formular generalizações e validar conjeturas.

Verbalizar, apresentar e registar raciocínios. Relativamente à forma como o aluno dá a conhecer o seu raciocínio no que regista no papel, destacam-se dois procedimentos: (i) recorrer somente à verbalização para explicar o seu pensamento sobre a interpretação da informação que retira do gráfico representado na calculadora; e (ii) registar simultaneamente a 
representação gráfica da calculadora e a verbalização de como interpreta a informação. Estes procedimentos verificaram-se, por exemplo, na resolução de dois pares de alunos à seguinte tarefa:

No início de 1972, havia quatrocentos lobos num determinado parque natural. As medidas de proteção fizeram com que o referido número aumentasse continuamente. Os recursos do parque permitem que o número de lobos cresça até bastante perto de um milhar, não permitindo que este valor seja ultrapassado.

Nestas condições, apenas uma das expressões seguintes pode definir a função $\mathrm{P}$ que dá o número aproximado de lobos existentes no parque natural, $t$ anos após o início das medidas de proteção:
(A) $\frac{1000}{1+e^{-0,5 t}}$
(B) $\frac{1000}{1+1,5 e^{-0,5 t}}$
(C) $\frac{1200}{1+2 e^{-t}}$
(D) $1000-\frac{600\left(t^{3}-1\right)}{e^{t}}$

Qual é a expressão correta? Numa composição, com cerca de dez linhas, explica as razões que te levam a rejeitar as outras três expressões (apresenta três razões diferentes, uma por cada expressão rejeitada).

$\mathrm{Na}$ resolução desta tarefa, houve alunos que recorreram à representação gráfica de cada uma das funções, aliada à informação que é fornecida no enunciado, para justificar as razões que os levaram a rejeitar cada uma das expressões.

Figura 8: Resposta dos alunos sem gráfico (P5).

\begin{tabular}{|c|c|}
\hline $\begin{array}{l}(A)=500 \\
(B)=400 \\
(C)=400 \\
(D)=1600\end{array}$ & 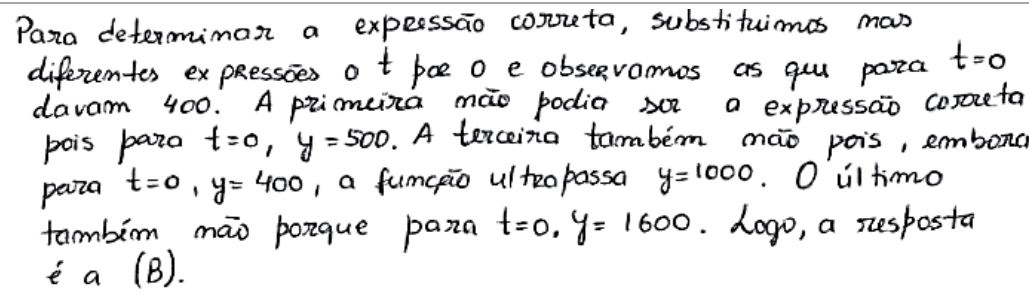 \\
\hline
\end{tabular}

No registo escrito do par $\mathrm{P} 5$, os alunos analisaram o número de lobos no instante inicial, rejeitando assim as opções A e D. Para decidir entre as opções C e B determinaram a assíntota horizontal, o que lhes permitiu verificar que o gráfico da expressão C ultrapassa o milhar de lobos estipulado. Neste caso, recorreram à calculadora, mas sem transcrever o esboço do gráfico, não tendo também apresentado justificações diferentes para cada expressão como era pedido. Outros alunos recorreram simultaneamente à representação gráfica e à verbalização das suas justificações para dar a conhecer os seus raciocínios, como exemplificam os registos elaborados pelo par de alunos P7 (Figura 9). 
Figura 9: Representação gráfica com justificação (P7).

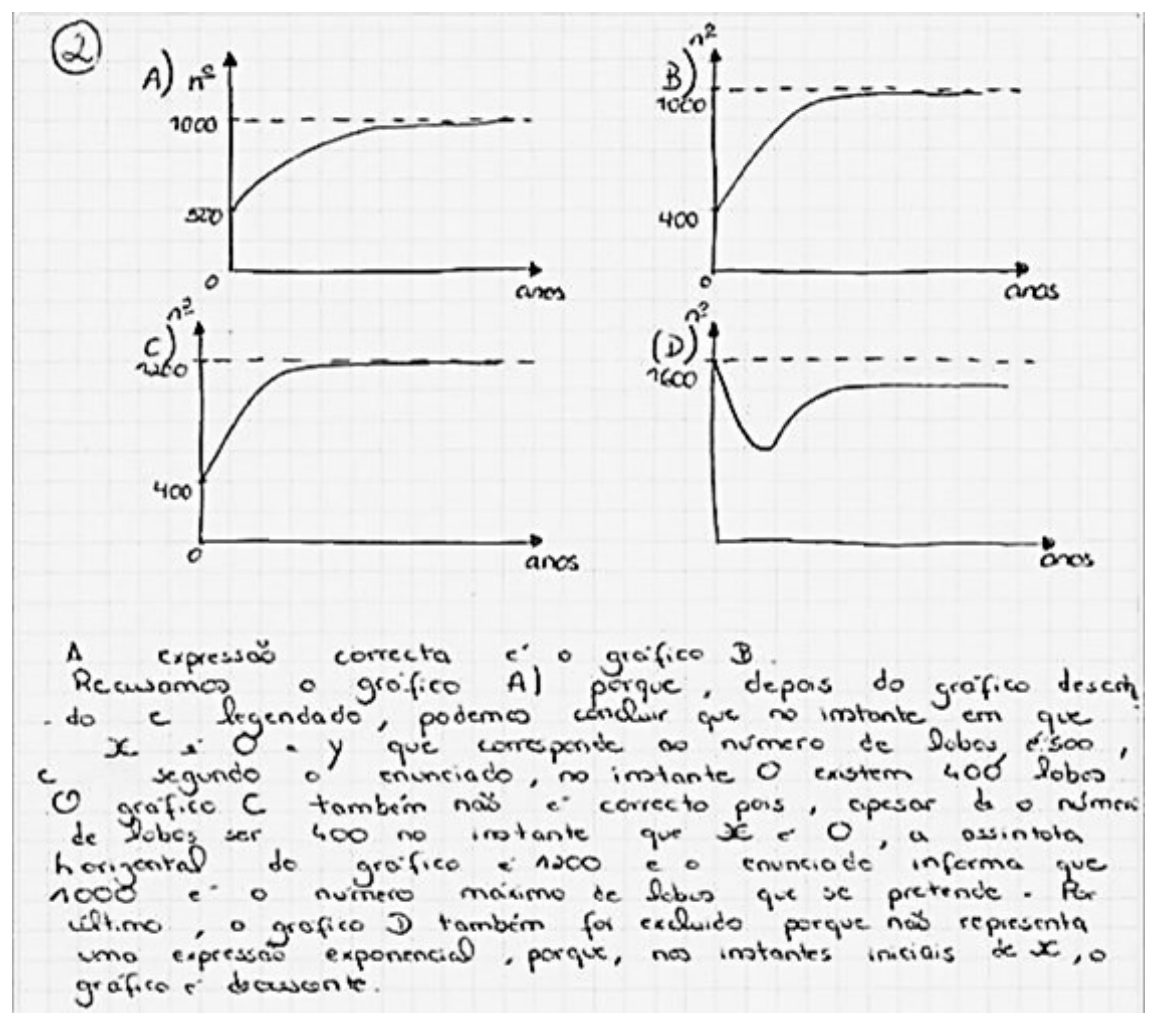

Nesta resolução, o par representou graficamente as quatro expressões e só depois tirou conclusões, indicando a opção correta e um motivo para rejeitar as restantes. Relativamente aos gráficos, denota-se algum rigor dos alunos na representação, tendo em conta o domínio da função, a assíntota dos gráficos de cada uma das funções e a indicação das variáveis nos eixos segundo a contextualização do problema. $\mathrm{Na}$ justificação que os alunos escreveram, apresentam um motivo para rejeitar cada um das opções incorretas.

Formular generalizações e validar conjeturas. Quando os alunos encontram um modelo para uma dada situação, têm de ver se é o que melhor se adequa, analisando, por exemplo, o coeficiente de correlação, como se verificou na resolução da seguinte tarefa:

Num estudo realizado em Portugal sobre o número de infetados pelo vírus da SIDA, efetuou-se a primeira recolha de dados no ano de 1988. A tabela seguinte apresenta os dados relativos ao número de infetados pelo vírus da SIDA em Portugal entre 1988 e 1996.

\begin{tabular}{|c|c|}
\hline Anos & $\mathbf{N}^{\mathbf{0}}$ de infetados \\
\hline 1988 & 522 \\
\hline 1989 & 891 \\
\hline 1990 & 1389 \\
\hline 1991 & 2032 \\
\hline 1992 & 2934 \\
\hline 1993 & 3940 \\
\hline 1994 & 5189 \\
\hline 1995 & 6764 \\
\hline 1996 & 8789 \\
\hline
\end{tabular}

Representa graficamente os dados e analisa a evolução do número de pessoas infetadas ao longo deste período de tempo. Que modelo melhor se ajusta aos dados registados? 
Nesta situação-problema, os alunos teriam de recorrer ao menu de estatística, inserir os dados nas listas, considerando o ano 1988 como sendo o ano 0, o ano 1989 como sendo o ano 1 e assim sucessivamente, e obter o diagrama de dispersão. Analisando a representação gráfica, os alunos conseguiriam ter uma ideia de qual seria o melhor modelo de ajustamento.

Os alunos introduziram os dados nas listas estatísticas da calculadora gráfica, recorreram ao modelo exponencial, afirmando que o coeficiente de correlação está muito próximo de um, sendo, por isso, um bom modelo para os dados apresentados (Figura 10).

Figura 10: Ajustamento do modelo exponencial aos dados (P1).

\begin{tabular}{|c|c|c|}
\hline List 1 & List 2 & $n^{2} \hat{\imath}$ \\
\hline 0 & 5.2 .2 & \\
\hline 1 & 891 & $x$ \\
\hline 2 & 1389 & $x$ \\
\hline 3 & 2032 & $x^{2}$ \\
\hline $\begin{array}{l}4 \\
5\end{array}$ & 3940 & $\longrightarrow$ \\
\hline 6 & 5189 & Exponencial: $\quad 0.34 x x^{t}$ \\
\hline $\begin{array}{l}7 \\
8\end{array}$ & $\begin{array}{l}6764 \\
8789\end{array}$ & $\begin{array}{l}y=644,5 \times e \times \\
z=0,99\end{array}$ e $x^{2}=0,98$ \\
\hline & & $\begin{array}{l}\text { ocoeficiente de correlac,ó é próximo } \\
\text { de } 1, \text { dogo é um bom modelo. }\end{array}$ \\
\hline
\end{tabular}

Contudo, outros alunos experimentaram outros modelos, recorrendo novamente ao valor do coeficiente de correlação ou mesmo ao facto de a curva passar por todos os pontos para validar o modelo exponencial como sendo o que melhor se ajusta aos dados. Com base nestes resultados, os alunos acrescentaram mais dados à lista e procuraram ver se o mesmo modelo se adequava aos novos dados. Ao acrescentarem os dados na lista da calculadora gráfica, a nuvem de pontos foi alterada, como se observa no registo do par P1 (Figura 11).

Figura 11: Ajustamento do modelo logístico aos novos dados (P1).

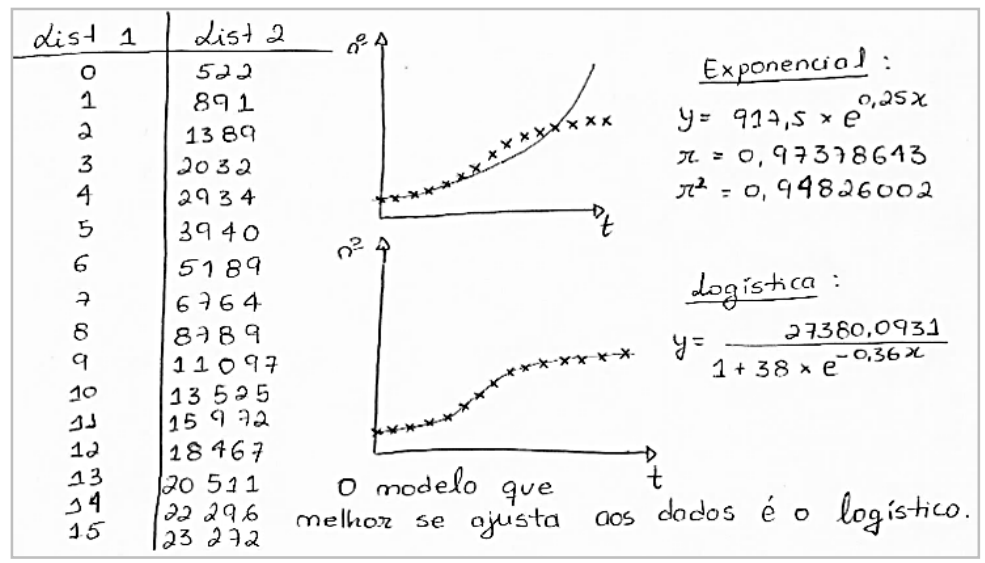

Apesar de o coeficiente de correlação continuar próximo de um, o esboço do gráfico não passa em todos os pontos. Tentaram, então, o modelo logístico, traçaram o gráfico e 
verificaram que passava em todos os pontos. Deste modo, validaram o modelo e consideraram-no como sendo o que melhor se ajusta a estes novos dados.

\section{Conclusões}

Da análise e interpretação dos dados recolhidos, constata-se que os alunos recorrem à calculadora gráfica para transcrever para o papel informação, estratégias de utilização da calculadora e expressar o seu raciocínio. Relativamente à informação que retiram da calculadora, os alunos registam sobretudo os esboços gráficos de modelos contínuos não lineares estudados sem qualquer verbalização escrita. Trata-se de um primeiro nível de utilização deste recurso, meramente instrumental, sobretudo quando as expressões que definem as funções não são familiares aos alunos. Como referem Waits e Demana (1994) e Dallazen e Scheffer (2003), a calculadora tem uma função utilitária na exploração de novos conceitos e procedimentos, bem como na resolução de tarefas que seria impraticável por outros meios.

Ao adquirirem uma maior habilidade na utilização da calculadora, os alunos manifestam cada vez mais à-vontade em trabalhar com este recurso, o que se traduz no registo das estratégias a que recorrem para tirar partido das potencialidades gráficas e numéricas da calculadora. Nessas estratégias destacam-se a definição da janela de visualização e a articulação entre os diferentes menus da calculadora. A definição da janela de visualização da calculadora é uma das estratégias mais importantes a desenvolver nos alunos (Consciência, 2013). Inicialmente, os alunos tendiam a representar graficamente uma função sem atender à definição dos intervalos que lhes permitia perceber o comportamento dessa função. Posteriormente, começaram a atender à janela de visualização, mas nem sempre registavam os intervalos que consideravam, o que indicia que esses intervalos resultavam de tentativas. A perceção acerca do aspeto gráfico de determinada expressão, da ordem de grandeza dos valores correspondentes às variáveis que contextualizam uma dada situação e das características da própria função são, segundo Consciência (2013), determinantes no registo dos intervalos da janela de visualização. No que diz respeito à articulação entre diferentes menus da calculadora, os alunos inicialmente utilizavam sobretudo o menu gráfico, e posteriormente estabeleceram conexões entre o menu gráfico e o menu tabela e entre o menu gráfico e o menu estatístico. Para Rocha (2002), esta capacidade desenvolve-se com a forma como os alunos integram a calculadora nas suas atividades de estudo sobre funções, designadamente quando relacionam o menu gráfico com o menu tabela. 
Relativamente à forma como organizam as suas respostas e dão a conhecer o seu raciocínio, os alunos, numa primeira fase, recorreram à calculadora para elaborar justificações sem apresentar o respetivo esboço gráfico. Numa segunda fase, tenderam a registar simultaneamente a representação gráfica da calculadora e a verbalizar a forma como interpretaram a informação. Assim, os alunos apercebem-se da importância que tem o confronto entre o que se pensa e regista com o que se vê. Para Ball e Stacey (2005), uma boa utilização da calculadora gráfica não dispensa o aluno de ter que pensar sobre a informação nela obtida, importando confrontar o que se obtém com o que se conhece.

Potenciar a capacidade de raciocínio dos alunos decorre também da formulação de generalizações e validação de conjeturas. Na generalização de um dado modelo, os alunos tiveram a oportunidade de discutir e decidir sobre o modelo que melhor se ajustava aos dados apresentados. Por vezes, o modelo que conjeturavam, num primeiro momento, como sendo o ideal para o problema em estudo era refutado e substituído por outros modelos com base na comparação dos coeficientes de correlação, que se revelavam superiores em valor absoluto. Para além desta comparação, os alunos validaram também as suas conjeturas através da análise dos esboços gráficos dos modelos encontrados, consoante as curvas se afastavam ou aproximavam dos pontos correspondentes aos dados. Como recomenda Lee (2010), o recurso a argumentos visuais na escrita matemática faz com que os alunos sintam a necessidade de ter a certeza do que interpretam e do que validam.

\section{Referências bibliográficas}

ANDERSON, M., BLOOM, L., MUELLER, U., \& PEDLER, P. (1999). The impact of the graphics calculator on the assessment of calculus and modelling. International Journal Mathematics Education Sciences Technology, 30, 489-498.

BALL, L. (2003). Communication of mathematical thinking in examinations: Features of CAS and non-CAS student written records for a common year 12 examination question. The International Journal of Computer Algebra in Mathematics Education, 10, 183-194.

BALL, L., \& STACEY, K. (2003). What should students record when solving problems with CAS? Reasons, information, the plan and some answers. In J. T. Fey, A. Cuoco, C. Kieran, L. Mullin, \& R. M. Zbiek (Eds.), Computer Algebra Systems in Secondary School Mathematics Education (pp. 289-303). Reston, VA: The National Council of Teachers of Mathematics.

BALL, L., \& STACEY, K. (2005). Good CAS written records: Insights from teachers. In H. Chick, \& J. Vincent (Eds.), Proceedings of the 29th conference of the international group for the psychology of mathematics education (Vol. 2, pp. 113-120). Melbourne: PME. 
BOGDAN, R., \& BIKLEN, S. (1994). Investigação qualitativa em educação: uma introdução à teoria e aos métodos. Porto: Porto Editora.

CONSCIÊNCIA, M. (2013). A calculadora gráfica na aprendizagem das funções no ensino secundário. Tese de doutoramento, Universidade de Lisboa, Lisboa, Portugal.

DALLAZEN, A. B., \& SCHEFFER, N. F. (2003). Calculadora gráfica no ensino e aprendizagem matemática. Acedido em 15 de Outubro de 2014 de http://miltonborba.org/CD/Interdisciplinaridade/Encontro_Gaucho_Ed_Matem/cientificos/C C22.pdf.

FERNANDES, J. A. \& VAZ, O. (1998). Porquê usar tecnologias nas aulas de matemática? Boletim da SPM, 39, 43-55.

FERNANDES, J. A., ALVES, M. P., VISEU, F., \& LACAZ, T. M. (2006). Tecnologias de informação e comunicação no currículo de Matemática do ensino secundário após a reforma curricular de 1986. Revista de Estudos Curriculares, 4, 291-329.

LEE, K. P. (2010). A guide to writing mathematics. Acedido em 15 de Outubro de 2014 de http://web.cs.ucdavis.edu/ amenta/w10/writingman.pdf.

MINISTÉRIO DA EDUCAÇÃO (2001). Programa de Matemática B (10. ${ }^{\circ}, 11 .^{\circ}$ e $12 .^{\circ}$ anos). Lisboa: Editorial do Ministério da Educação.

MORGAN, C. (1998). Writing mathematically: The discourse of investigation. London: Falmer.

ROCHA, H. (2002). A utilização que os alunos fazem da calculadora gráfica nas aulas de Matemática. Quadrante, 11, 3-28.

RUTHVEN, K. (1993). Personal technology and classroom change: A British perspective. In J. T. Fey (Ed.), Calculators in mathematics education (pp. 91-100). Reston: National Council of Teachers of Mathematics.

SANTOS, S. A. (2005). Explorações da linguagem escrita nas aulas de Matemática. In C. A. Lopes \& A. M. Nacarato (Orgs.), Escritas e leituras na Educação Matemática (pp. 127142). Belo Horizonte: Autêntica.

WAITS, B., \& DEMANA, F. (1994). Graphing calculator intensive calculus: A first step in calculus reform for all students. In A. Slow (Ed.), Preparing for a new calculus conference proceedings (pp. 96-102). Washington: The Mathematical Association of America. 